\title{
LA HUMANICIDAD COMO CATEGORÍA LINGÜÍSTICA Y CAMPO SEMÁNTICO-FUNCIONAL
}

\author{
Enrigue J. Vercher García \\ Universidad Complutense de Madrid \\ evercher@ucm.es
}

\section{Resumen}

El presente artículo plantea la existencia y analiza la categoría de bumanicidad, entendida como el modo en que las lenguas naturales clasifican y expresan la realidad externa en dos grandes ámbitos: el ámbito humano (aquel que el hablante entiende como perteneciente a la sociedad humana, a la esfera de la vida, costumbres, rituales, civilización y cultura específicamente propios del ser humano) y el ámbito natural (la esfera de todo aquello ajeno a la comunidad humana, de lo que está fuera del área de influencia de la civilización humana, es decir, los fenómenos naturales, flora y fauna en su estado salvaje no "domesticado" o no "civilizado").

El campo-semántico funcional de la bumanicidad sería el conjunto de recursos de los diferentes niveles lingüísticos (fonéticofonológico, morfológico, sintáctico y léxico) de una lengua dada para configurar los referentes de la realidad y clasificarlos en función de su categoría de humanicidad (ámbito humano vs. ámbito natural). La humanicidad, por tanto, no debe ser confundida con fenómenos bien conocidos como los de animacidad lingüistica o la distinción morfosintáctica entre bumano/ no bumano.

Palabras clave: lingüística, linguoculturología, lenguaje, lenguas naturales, ámbito natural, ámbito humano, categorías lingüísticas, humanicidad, campo semántico-funcional.
Title: Humanicity as a linguistic category and functional-semantic field

\begin{abstract}
This article proposes the existence and analyses the category of humanicity, understood as the way in which natural languages classify and express external reality in two large fields: the human sphere (which the speaker understands as belonging to human society, the area of life, customs, rituals, civilization and culture specific to human beings) and the natural sphere (the sphere of everything outwith the human community, outwith the area of influence of human civilization; that is, natural phenomena, flora and fauna in their wild, "undomesticated" or "uncivilised" state).

The functional-semantic field of bumanicity would be the set of resources of the different linguistic levels (phonetic-phonological, morphological, syntactic and lexical) of a given language for configuring the reference points of reality and classifying them based on their category of humanicity (human sphere vs natural sphere). Humanicity, must therefore not be confused with well-known phenomena such as linguistic animacy or the morphosyntactic distinction between buman/non-human.
\end{abstract}

Keywords: linguistics, linguoculturology, language, natural languages, natural sphere, human sphere, linguistic categories, humanicity, functional-semantic field. 


\section{INTRODUCCIÓN}

El punto de arranque del estudio y de las reflexiones que ofrecemos aquí es el de algunos fenómenos muy corrientes que cualquier hablante puede percibir. Así, por ejemplo, en la distinción en español entre pez/pescado, el primero se refiere al animal vivo, dentro del agua, en su medio natural (naturaleza), mientras que el segundo vocablo se refiere al mismo animal, pero ya capturado por el ser humano para su consumo (por tanto, se encuentra en el ámbito humano).

En efecto, la lengua establece una distinción entre un ámbito humano y un ámbito no humano (o natural). Un mismo objeto, animal, fenómeno o suceso puede ser tratado (y valorado) de manera distinta en función de si los hablantes de un idioma dado lo consideran como perteneciente al ámbito humano o como perteneciente al ámbito natural. Aunque en las numerosas obras dedicadas a la descripción lingüística (gramaticales, morfosintácticas, léxicas) de las distintas lenguas podemos encontrar ejemplos de este fenómeno, no nos consta ningún estudio de conjunto que abarque y sistematice esta categoría que proponemos en el presente artículo.

De este modo, una misma realidad física puede ser distinguida por los hablantes de un idioma en función de que la consideren como perteneciente al ámbito humano o al ámbito natural, y de hecho una misma cosa puede ser percibida inicialmente como perteneciente al ámbito natural para pasar posteriormente a formar parte del ámbito humano. Pongamos como ejemplo de esto último la extremidad de un cordero; podrá ser denominada pata de cordero cuando se refiere al animal en su estado natural, vivo (ámbito natural) o como pierna de cordero cuando se refiera a una comida y por tanto perteneciente al ámbito humano (ámbito humano). El referente físico es el mismo (la extremidad del cordero), lo que varía es el ámbito en que se circunscribe en cada caso.

El ámbito humano habitualmente (pero no siempre) será el elemento marcado frente al ámbito natural, que será el no marcado. Así, en principio, el vocablo fuego podría usarse tanto para el ámbito natural como para el ámbito humano (la hoguera), pero no al revés, hoguera como vocablo pertenece estrictamente al ámbito humano y no se usará nunca cuando se trate de fuego en estado natural. El hablante puede referirse a un pescado que esté en su plato como pez, pero nunca se referirá a peces vivos en su ámbito natural (imaginemos un documental que esté hablando de peces) como pescados (excepto, lógicamente, si hay alguna intencionalidad humorística). Con todo y con eso, no se trata de un rasgo que se dé de manera estricta, puede haber casos en los que los dos elementos estén claramente identificados como pertenecientes al ámbito humano o al ámbito natural. 
Este fenómeno lingüístico puede considerarse universal y supone un modo básico de configurar el lenguaje inherente al habla humana. Ahora bien, sus manifestaciones son muy distintas de unas lenguas a otras, lo que significa que se trata de un elemento linguoculturológico ${ }^{1}$ que configura y manifiesta de manera diferente en cada lengua la forma en que los hablantes distinguen entre ámbito humano y ámbito natural (no-humano). Esto significa, además, que nos referimos al uso hablado de una lengua dada según sus hablantes nativos, no del lenguaje científico ni la categorización científica del mundo.

Existe, pues, una categoría lingüística que podríamos denominar bumanicidad, que afecta a la forma y contenido de los elementos lingüísticos en el modo que hemos indicado (ámbito humano/ámbito natural). Dicha categoría lingüística se estructuraría en cada lengua en un campo semántico-funcional siguiendo la terminología de A. V. Bondarko². La metodología lingüística de A. V. Bondarko y su equipo parte de algunos conceptos básicos de la gramática funcional, como no dividir la lengua en diferentes niveles aislados (fonología, morfología, sintaxis, etc.) ni partir del mero estudio de las formas lingüísticas, sino que integra todos los niveles al concebirlos interrelacionados, busca las funciones que existen en la lengua y que constituyen el verdadero mecanismo del lenguaje y lo analiza "de la función a la forma" y "de la forma a la función". Noción central en la teoría de A. V. Bondarko es la de campo semántico-funcional (CSF). El campo semántico-funcional vendría a analizar los distintos mecanismos de los que se vale cada una de las categorías semánticas fundamentales (aspectualidad, modalidad, temporalidad, determinación/ indeterminación, etc.) para expresarse en cada lengua. Si un campo semánticofuncional está constituido sobre todo por un mecanismo concreto especializado en una lengua determinada en expresar una categoría semántica, hablaremos de campo semántico-funcional monocéntrico (por ejemplo, el campo semántico-funcional de la aspectualidad en ruso, puesto que está dominado por el aspecto verbal presente en todos los verbos en esa lengua). Si carece de un centro predominante estaremos hablando de uno policéntrico (vid. Bondarko, 1987, 1990, 1992).

En el presente trabajo planteamos y analizamos la existencia de una categoría lingüística que denominamos humanicidad, que se estructuraría en las distintas

\footnotetext{
Término lingüístico ampliamente usado por la literatura científica rusa y que se define como «disciplina científica compleja que estudia la interrelación e interacción entre cultura y lengua en su funcionamiento y que refleja este proceso como una única estructura integral de unidades de contenido lingüístico y extralingüístico (cultural) [Vorob’ëv, 1994: 26]» (Vid. Vorob’ëv, 1994; Maslova, 2004) y cercano al de visión lingüistica del mundo, aunque algunos autores los distinguen.

2 Vid. Bondarko (1987) y resto de amplia bibliografía dedicada por el autor a la gramática funcional y a la teoría de los campos semántico-funcionales.
} 
lenguas en un campo semántico-funcional policéntrico (carece de un centro -un recurso lingüístico- dominante), y que haría referencia al modo en que las distintas lenguas distinguen con variados recursos lingüísticos entre un ámbito humano frente a un ámbito natural. El marco teórico y la metodología base de nuestro estudio se circunscribirían a la linguoculturología y visión lingüística del mundo de Arutjunova (1999), Bach y Harms (1968), Comrie (1989) Maslova (2004) y Stepanov (2004) y a la teoría de los campos semántico-funcionales de Bondarko (1987, 1990, 1992), tomando como objeto de estudio las descripciones lingüísticas de diferentes idiomas del mundo. No existen estudios previos cuya base sea la de la categoría de humanicidad tal y como la presentamos aquí, aunque sí existen numerosos trabajos sobre algunos de los recursos lingüísticos con los que cuentan las lenguas para expresar dicha categoría (por ejemplo, la distinción morfológica y sintáctica entre humano/no-humano).

La categoría de humanicidad se manifiesta en distintos niveles de la lengua (morfológico, sintáctico y léxico) y está relacionada (pero no debe confundirse) con otros fenómenos lingüísticos bien conocidos y estudiados, como puedan ser la animacidad (carácter animado/inanimado) o la distinción entre humano/no humano ${ }^{3}$. Por ejemplo, dos animales (no humanos) distintos pueden ser tratados de manera distinta en las lenguas naturales según pertenezcan al ámbito humano (doméstico, domesticado, civilizado...) o al ámbito natural (no humano, salvaje). No estamos, por tanto, ante una distinción entre animado/inanimado ni humano/ no humano, sino ante una distinción entre ámbito humano / ámbito natural.

Así pues, la distinción en ruso entre el acusativo masculino para seres animados (чемовека [čeloveka] 'persona', господина [gospodina] 'señor', кота [kota] 'gato', журавмя [žuravlja] 'grulla..., formalmente igual que el genitivo) y seres inanimados (кес [lex] 'bosque', чемодан [čemodan] 'maleta', пейзаж [рејzaż, del francés paysage] 'paisaje', сон [son] 'sueño', сюрреализм [sjurrealizm, del francés surréalisme] 'surrealismo'..., formalmente igual que el nominativo) no sería el objeto de estudio del presente trabajo (vid. Akademija Nauk SSSR, 1980).

La conocida distinción entre humano/no-humano puede ser uno más de los recursos de los que se vale una lengua dada para manifestar la categoría de humanicidad, pero no tiene por qué ser el único ni se deben identificar plenamente estos dos conceptos lingüísticos (del mismo modo que el campo semántico-funcional de la aspectualidad se vale en ruso principalmente del aspecto sin que se deban confundir

\footnotetext{
La bibliografía sobre este tema es demasiado extensa como para referenciarla aquí, baste citar a autores que han abordado esta cuestión como Beard (1995), Becker (2014), Comrie (1989), Corbett (1980), Croft, Dahl (1996), Fraser (1994), Klenin (1983), Leech, Francis \& Xu (1994), McLaughlin (2014), Marlett (2012), Sorlin y Gardelle (2018) o Yamamoto (1999).
} 
estos dos conceptos). La distinción entre humano/no-humano es, por tanto, pertinente en nuestro estudio, pero no se refiere exclusivamente a ella ni deber confundirse con la categoría de la humanicidad.

Debemos recalcar que tampoco estamos hablando de la "subjetividad" o el "antropocentrismo" en el lenguaje humano, tan ampliamente estudiados y que serían conceptos más amplios ${ }^{4}$, sino de los recursos lingüísticos de las lenguas para diferenciar explícitamente el ámbito humano frente al ámbito natural de una misma realidad dada (partes del cuerpo, elementos de la naturaleza, relaciones entre individuos, etc.).

Pasamos a analizar en detalle los recursos en diferentes niveles lingüísticos de distintas lenguas para categorizar la humanicidad y distinguir entre ámbito natural y ámbito humano.

\section{NiVEL LÉXICO}

Vamos a comenzar nuestro análisis por el nivel léxico por ser el más evidente y el de mayor relevancia por el elevado número de ejemplos. Como hemos comentado, la distinción de los dos grupos de la categoría de humanicidad, según la entendemos, se da principalmente en aquellas realidades que pueden estar presentes tanto en el ámbito humano como en el ámbito natural. Hablamos de elementos de la naturaleza (agua, fuego...), de animales, de vegetales, de partes del cuerpo, etc.

Veamos algunos ejemplos y analicémoslos:

\section{- Partes del cuerpo:}

Más allá de denominaciones científicas, el hombre desde antiguo ha hecho una distinción entre las partes comunes del cuerpo que puedan tener animales y hombres. Sería el caso de palabras como patas/piernas, pelo/cabello, pezuña/mano-pie, vibrisas/bigote, etc. Pero según nuestra propuesta de la existencia de una categoría o campo semántico-funcional de humanicidad, más allá de la distinción entre humano/no-humano, existe también en el lenguaje una distinción entre que un mismo referente pertenezca al ámbito de los humanos o no. Veamos algunos ejemplos:

\footnotetext{
Nuevamente nos encontramos con un campo de estudio vasto con una numerosísima bibliografía imposible de abarcar aquí pero que iría desde los estudios sobre modalidad (por ejemplo, Bondarko, 1990; Palmer, 1986), subjetividad (Rey, 1999-2000), antropocentrismo lingüístico (Arutjunova, 1999), valoración (Vol'f, 2002), la connotación (Fartakh, 1997; Jiménez Ruiz, 1986), relación entre pensamiento y lenguaje (Wittgenstein, 2017; Krivonosov, 2012), etc.
} 
Patas/piernas: adviértase que en este caso, cuando una pata pasa al ámbito humano (como alimento), frecuentemente se produce precisamente un traspaso de categoría; así, por ejemplo, decimos en español pierna de cordero, manitas de cerdo como nombres de platos, y no pata de cordero o pezuñas de cerdo. Esto es así porque la extremidad de un animal no está determinada lingüísticamente solo por la categoría de humano/no-humano, sino por la de ámbito humano/ámbito natural, que aquí estudiamos. Cuando el hablante de español se refiere a la extremidad de un animal en su estado salvaje o natural (ámbito natural), usará la palabra pata, mientras que se referirá a esa misma extremidad cuando esté ya dentro del ámbito humano (como comida, nombre de plato, por ejemplo) como pierna. La dificultad para percibir y describir la categoría de humanicidad es que no está tan claramente delimitada ni marcada lingüísticamente como otras categorías, es solo una tendencia por parte de las lenguas a distinguir el ámbito humano del ámbito natural.

Pelo/cabello: lo que encontramos aquí realmente es una distribución taxonómica de los vocablos, siendo pelo el genérico (y puede ser usado, por tanto, referido al ámbito humano como al ámbito natural) del que partirían dos nodos: por un lado, el del ámbito humano, que incluiría la palabra cabello, y por otro lado, el del ámbito natural, donde encontraríamos vocablos como crin o cerdas.

\section{- Género y edad:}

Conceptos relacionados con el sexo, la edad y otras circunstancias del desarrollo fisiológico también suelen ser susceptibles de la distinción entre ámbito natural y ámbito humano: macho, hembra/varón, mujer (ruso: самец [samets], самка [samka]) мужчина [mužcina], женщина [ženšcina]; inglés: male, female/man, woman); crial hijo (ruso: детёныш [detënys']/ребёнок [rebënok], euskera: kume/seme).

Como señala Yu. S. Stepanov [2004], cuanto más importante es algún concepto en una cultura, más parametrizado está. Probablemente el concepto más parametrizado a nivel universal sea el de hombre, ser humano. El citado autor presenta como ejemplos varón que se definiría como 'ser humano en contraposición a la mujer por sexo', y a partir de ahí marido ('varón con respecto a una mujer con la que tiene una relación de matrimonio'), padre ('varón con respecto a sus hijos'), maestro ('varón que enseña, con respecto a sus alumnos'), y un largo etc., con todos sus equivalentes aplicados a mujer.

En el caso de la catalogación de los seres por su edad, en protoindoeuropeo encontramos también ejemplos de esta distinción: * ${ }^{*}$ erabh- [protoesl. *̌verbъ, *žerbьcь, *̌̌erbēe de donde procederían formas como rus. жеребёнок 'potro'] 'joven en ámbito no humano, * kat- [protoesl. *kotъ 'cría', umbr. katel] 'joven (ámbito 
no humano), cría, *stādh- [rus. cтаAo, protogerm. * stōod-a-, ${ }^{*}$ stōod-o, ${ }^{*}$ stad-jō, -an-] 'animales y plantas jóvenes', frente a *maghó-, *maghu-, *maghos [avést. magava 'hombre soltero' ing. maid 'doncella, mujer no casada'] 'joven (ámbito humano), soltero', *mery- 'hombre joven', 'mounos 'persona joven', *puH-, *pupos 'niño', *ieHw3-g, 'joven' y * $H_{2} i w-w H_{1} n k o ́-,{ }^{*} H_{2} i w-w H e n$, *yowen- 'joven, persona joven' (vid. Bronnikov \& Krylov, 1998-2014; Roberts \& Pastor, 2009).

\section{- Animales y vegetales:}

En realidad, podríamos establecer una primera diferenciación entre humano (ser humano)/no humano (animal), y a nivel de animales una segunda diferenciación entre animales domésticos (ámbito humano) y animales salvajes: bestia (doméstico)/fiera (salvaje).

La oposición entre ámbito natural y ámbito humano, en lo que se refiere a animales, puede manifestarse en base a distintos criterios. Uno sería el de las distintas variedades (doméstica frente a salvaje o silvestre) de una misma especie. La forma doméstica, la del ámbito humano, que puede ser la cultivada por el hombre en caso de vegetales o domesticada en el caso de animales, en muchos casos es la forma básica genérica, siendo la variedad salvaje o silvestre la específica, con lo que en este caso la forma perteneciente al ámbito natural sería el elemento marcado.

Ejemplos de este primer criterio de distinción serían casos como el de acebuche (olivo silvestre)/olivo (término no marcado que puede usarse tanto en el ámbito humano como hiperónimo genérico); en inglés mustang ( 'caballo salvaje'; en este caso el vocablo del ámbito natural es el marcado)/horse ('caballo'; término no marcado que puede usarse tanto en el ámbito humano como hiperónimo genérico).

Un segundo posible criterio de clasificación entre ámbito natural y ámbito humano en el caso de animales y plantas sería el de su uso como alimento humano. Un animal o una planta pueden tener una denominación en una lengua dada cuando están en su ámbito de la naturaleza, y otro si ese mismo animal o planta se usa como comida humana.

Sería el caso de pez/pescado; cacabuete/mani; o en ruso спинка (lomo de los peces)/балык (lomo de pescado preparado como plato, normalmente curado); свиня [svinja] (cerdo, el animal)/свинина [svinina] (carne de cerdo para ser consumida).

La distinción de los lexemas que pertenecen a este grupo parece ser bastante estricta, los que pertenecen al ámbito humano no pueden ser usados aplicados al ámbito natural, ni a la inversa, lo que da idea de que precisamente el uso de animales y plantas como alimento humano es uno de los casos más básicos y primitivos en que los hombres distinguieron en su lenguaje los dos ámbitos. 
Otro tercer posible criterio de distinción entre ámbito natural y ámbito humano sería el de su utilidad para el ser humano. Así por ejemplo la distinción entre madera /leña, donde madera sería el elemento perteneciente al ámbito natural (y usado como genérico del material), frente a leña, que sería el elemento perteneciente al ámbito humano, y en concreto a la madera usada para crear fuego doméstico. Esta distinción se da también en otros idiomas: rus. Аерево [derevo]/Арова [drova]; ingl. wood/firewood.

\section{- Otros campos:}

Los elementos naturales son uno de los ejemplos más claros de la distinción que hace el lenguaje humano en función de que se asocien a su estado natural, presente en la naturaleza, por un lado, y su control y uso por parte del ser humano, por otro lado. Nuevamente vemos en este campo semántico que el elemento marcado será el del ámbito humano.

Así, encontramos ejemplos como los de fuego/hoguera (ing. fire/bonfire; rus. огонь [ogon']/костёр [kostër]; lat. focus/pyra). En el caso del fuego y vocablos de su campo semántico, encontramos en el indoeuropeo la distinción entre la raíz ${ }^{*} H_{1}$ égni- [lat. ignis 'fuego, rayo, centelleo', rus. огонь 'fuego, luz'] 'fuego en la naturaleza', y también probablemente ${ }^{*} H_{1} e H_{2}$ ter-, $\left.{ }^{*} a ̄ t-(-t h-)<P I H{ }^{*} H-\right\rangle$ [avést. ātarš, neopers. āđar 'fuego'] por un lado, frente a ${ }^{*} p u e-r / n-,{ }^{*} p w \bar{o}-\left\langle P I H^{*}-H^{w_{-}}\right\rangle$, ${ }^{*} p e ́ H_{2}$ wr- ( ${ }^{*}$ bhlagsma) [gr. $\pi \tilde{\rho} \rho$ 'fuego, fuego del cielo, rayo, luz de antorchas', $\pi v p \dot{\alpha}$ 'pira, fuego sobre el altar'; lat. flamma 'llama', ing. fire] 'fuego en ámbito humano, hoguera, pira', por otro lado (vid. Bronnikov \& Krylov, 1998-2014; Roberts \& Pastor, 2009).

En el caso de agua y su campo semántico, podría rastrearse esa distinción entre ámbito natural y ámbito humano en la etimología de formas como onda, linfa y agua. En latín se aprecia mejor esta distinción y constituye uno de los pocos casos en que el vocablo del ámbito humano (aqua) es el término no marcado frente a vocablos que designan este elemento específicamente en la naturaleza (unda, lympha). Así, el vocablo aqua designa al elemento, el agua, en general, y es el usado, entre otros casos, en el ámbito humano para referirse al agua almacenada o para beber. Frente a dicho vocablo encontramos otros que designan al agua específicamente en formas de la naturaleza, como serían unda ('agua en movimiento, cuerpo de agua fluyente -de un río, por ejemplo-) o lympha ('agua cristalina que surge de una fuente o manantial').

En este sentido, en protoindoeuropeo encontramos por un lado la raíz ${ }^{*} \mathrm{H}_{2} e \mathrm{Hp}^{-},{ }^{*} \mathrm{H}_{2} e k^{w} e \mathrm{H}_{2},{ }^{*} \mathrm{H}_{1} e w g^{w} h,{ }^{*} H_{1} w e g^{w} h,{ }^{*} a k^{w}$ - con el significado de 'gua 
fluyendo, río, de la que provendrían etimológicamente las formas lat. aqua, hit. akukal, protogerm. ${ }^{*} a(g) w o,{ }^{*}{ }^{*} x w \bar{o} ;{ }^{*} \overline{\mathrm{o}}(\mathrm{g}) w j \mathrm{a}^{\prime} \mathrm{z} ;{ }^{*} a(g) w j \bar{o}$, frente a las formas de la raíz ${ }^{*}$ wed-y sus derivaciones ( ${ }^{*}$ wedr, ${ }^{*}$ wed-o-, ${ }^{*}$ wod-r-, ${ }^{*}$ wod-or, ${ }^{*}$ wod-en, ${ }^{*} H w r,{ }^{*}$ weri,

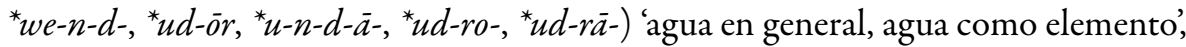
de donde procederían las formas lat. unda, hit. watar, protogerm. *wat-an-, *wat-ar$n$, rus. вода, ing. water. Como podemos observar, curiosamente, en latín se produjo una inversión del uso de las palabras usadas en ámbito humano y ámbito natural con respecto al protoindoeuropeo, lo que no ocurre en otras familias del filo (cfr. protogermánico *a(g)wó, *áxwō; *ō(g)wja-z; *a(g)wjố 'río (aguas en su ámbito natural)' < PIE *ak ${ }^{\mathrm{w}}$ - vs. wat-an-, *wat-ar- $n$ 'agua (como elemento en general, término no marcado, y también en el ámbito humano)' < PIE *wed-, *wod-r-, *wodor, *wod-en) (vid. Bronnikov \& Krylov, 1998-2014; Roberts \& Pastor, 2009).

Bastante representativos de la distinción entre ámbito natural y ámbito humano son los colores. Taxonómicamente una lengua como el español distingue entre unas denominaciones genéricas para los colores (blanco, negro, rojo, naranja, amarillo, verde, azul, marrón, gris, rosa y violeta $)^{5}$, denominaciones para colores aplicados al ámbito natural, por ejemplo, colores de animales (zaíno, albabio, cárdeno...), y denominaciones para colores aplicados al ámbito humano (rubio, castaño, pelirrojo...). En este caso, la tendencia de las lenguas universales a ser muy específicas en la descripción cromática del mundo se une a la distinción entre ámbito humano y ámbito natural, lo que da lugar a denominaciones de colores propias del ámbito humano y otras propias del ámbito natural.

Otro ejemplo léxico sería el de la agrupación de individuos no humanos / humanos. Así, tenemos en español vocablos comojauría, manada/clan, tribu, familia, tropel, cuadrilla, muchedumbre (y otras muchas palabras para designar la agrupación de personas).

Esta distinción la registramos ya en el protoindoeuropeo: *sle $H_{1} i u$, *slak-, *slowg ${ }^{h}$ os 'multitud no humana', del que proceden formas como ing. slew 'montón',

5 Como curiosidad podemos señalar que estos serían los colores básicos con los que el hablante de español clasifica los colores. La tradicional asignación de siete colores al arco iris que tiene su origen en Isaac Newton se debe a su creencia en la Ley de los sietes, según la cual el universo estaba regido siempre por siete elementos (siete planetas, siete metales usados en alquimia, siete notas musicales, etc. etc.). Lo cierto es que estrictamente hablando para los nativos de español hay 11 colores básicos; colores como el celeste, el añil, etc., serían tonalidades del azul. No ocurre así para los hablantes de ruso, quienes distinguen entre голубой (azul claro o celeste) у синий (azul oscuro o añil) como dos colores básicos diferentes. Para un estudio sobre los términos y categorías básicas del color en español vid. Collado Vega (2016), quien muestra las diferencias diatópicas (entre español de España, México, Uruguay, etc.) e incluso por sexo en la categorización de los colores. Para un estudio clásico de los colores en las lenguas vid. Berlin \& Key, 1969. 
y *(s)trent- 'multitud (de animales), rebaño, manada', del que se derivarían formas como protoesl. *trōt $\mathbf{b}$ 'multitud, montón', rus. ant. трутъ 'grupo, multitud'

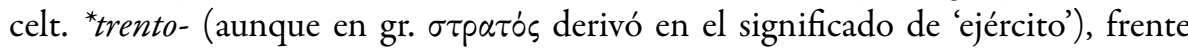
a *pledhwis, * ${ }^{*} l e ́ h_{1} d^{h} u h_{1}$ 'multitud (humana)', del que derivan formas como el lat. plebs 'plebe', ${ }^{*}(s) k^{w} e l$ - 'multitud, gente, grupo de personas', del que derivan formas como ing. ant. scolu 'banda, tropa, grupo de personas', rus. человек 'persona' (vid. Bronnikov \& Krylov, 1998-2014; Roberts \& Pastor, 2009).

Aprovechamos para comentar que este doble ámbito de aplicación explicaría los dobletes semánticos que existen en indoeuropeo, fuera de variantes geográficas y temporales debidas a la evolución y propagación de esta protolengua. Esta motivación humano/no humano no excluye otros contenidos semánticos presentes en las formas protoindoeuropeas y de otras lenguas

\section{NiVEL MORFOLÓgICO}

Encontramos en las lenguas también a nivel morfológico muchos recursos para especificar la categoría de humanicidad. Como estamos viendo que ocurre con esta categoría, la mayor parte de las veces no se trata de un conjunto de recursos sistematizados, sino de una serie de recursos que varían de una lengua a otra pero que de un modo u otro sirven para distinguir entre el ámbito natural y el ámbito humano.

Un caso lo veíamos ya en uno de los ejemplos expuestos, el de свиня (cerdo, el animal)/свинина (carne de cerdo), ya que el ruso posee el sufijo -ина destinado precisamente a designar la carne de algún animal destinada a ser consumida (ámbito humano). Así, tenemos formas como телёнок [telënok] 'ternero'/телятина [teljatina] 'carne de ternera', баран [baran] 'carnero'/баранина [baranina] 'carne de carnero', говядо [govjado] (arc. y dial.) 'animal bovino (toro, buey, vaca)'/говядина [govjadina] 'carne de bovino'.

En la lengua niuana, una lengua polinesia, el prefijo kau- designa un 'grupo de personas', así por ejemplo kawvaka (kau + vaka 'barca') 'tripulación de una barca' (vid. Polinskaya, 1995).

Morfemas del español del ámbito específicamente humano serían: - azgo 'título, demarcación' (mayorazgo, almirantazgo, cacicazgo, noviazgo...); -cidio 'asesinato o eliminación (referido expresamente a grupos o individuos humanos)' (bomicidio, genocidio, infanticidio, parricidio, magnicidio, tiranicidio...); -crata 'defensor de un sistema o perteneciente a un grupo de poder' (demócrata, ácrata, tecnócrata, aristócrata...); -eco, -ego, -eño o -ense como gentilicios (zapoteco, mixteco, manchego, gallego, madrileño, sureño, nicaragüense, bonaerense...); -latra 'persona que adora' 
(ególatra, idólatra, demonólatra, zoólatra...). Obsérvese que estamos hablando de morfemas que aparecen exclusivamente en lexemas del ámbito humano. Hay otros morfemas que si bien pueden referirse a lexemas del ámbito humano, también aparecen en el ámbito no humano y, por tanto, no los consideraremos dentro de este grupo (por ejemplo los sufijos -or, -dero, etc.). Obsérvese también que estamos hablando de afijos con un significado específico del ámbito humano y no de simples terminaciones por cuestiones etimológicas.

Evidentemente incluiríamos también morfemas específicamente de ámbito humano (profesiones, gentilicios...), v. gr. en lituano los sufijos -tojas, -ejas o -ininkas (mokytojas 'profesor', pardavejas 'vendedor, dependiente', ukininkas 'granjero', etc.) (vid. Ambrazas, 1997).

Entre los morfemas del español relativos al ámbito no humano tendríamos -aceo 'perteneciente a una familia de animales o plantas' (crustáceo, oliváceo, herbáceo, aceráceo...); - -ato 'cría de animal' (ballenato, lobato, jabato, cervato...); -eda 'lugar donde abunda (una determinada especie)' (arboleda, alameda, avellaneda, rosaleda...).

En nuestra opinión la aparición del caso vocativo en muchas lenguas es una manifestación de esta tendencia del lenguaje humano a especificar el ámbito humano, ya que, en principio, es un caso expresamente destinado a ser usado con seres humanos para llamarlos (u objetos personificados), ejemplos: polaco mama (nom.)/mamo! (voc.) 'mamá; lituano Petras (nom.)/Petrai! (voc.) 'Petras (nombre propio)'; o el vocativo coloquial en ruso Hamama (nom.)/Hamau! (voc.).

A nivel morfológico, evidentemente, uno de los recursos lingüísticos más importantes del campo semántico-funcional de la humanicidad es la distinción entre humano/no-humano que presentan numerosas lenguas. Veamos algunos ejemplos:

El chino distingue entre un pronombre de tercera persona de plural para humanos (他们, y también 她们 'ellas' específicamente para mujeres) y para no humanos (它们). Este fenómeno lo encontramos en muchas otras lenguas, como por ejemplo finés: he ('ellos (humanos)')/ne ('ellos (no humanos)') ${ }^{6}$.

Es curioso que, aunque en chino existe una sola forma de pronombre de tercera persona de singular $(t \bar{a})$, en la escritura sí se distingue entre un sinograma para hombre o de género indeterminado (他), otro para mujer (她), otro para deidades (祂) y otro para animales (牠) (Vid. Yip \& Rimmington, 2015).

La lengua yuki (lengua aislada muerta de la actual California) distinguía dos clases de sustantivos: humanos y no-humanos. Así, los sustantivos humanos con función gramatical de paciente están marcados con el caso paciente y el caso oblicuo se añade a la forma de dativo del sustantivo (humano), mientras que los sustantivos 193-195]. 
no-humanos con función de paciente no están marcados y el caso oblicuo se añade directamente a la raíz del sustantivo (no-humano).

Compárese la oración są'ey 'ú:t>mil t’úy hulk'o?ả 'y entregó la resina al coyote' (donde hulk'o'á 'coyote' - no humano- es el paciente que recibe la acción del verbo 'ú:t>mil) frente a ki'at haw 'i: ča:nik' 'me dio su (=de otro) pescado' (donde ki'at 'me (pronombre personal en dativo -humano-) es el paciente que recibe la acción del verbo) (vid. Balodis, 2016).

El idioma abjasio (lengua caucásica) distingue dos clases de sustantivos basados en la categoría de humanicidad, y no en la distinción entre animado/inanimado: humano y no humano. Así, por ejemplo, los sustantivos humanos forman el plural añadiendo (el abjasio es una lengua predominantemente aglutinativa) el sufijo -цәа (азһабцәа 'muchachas', ашәкәыєецәа 'escritores'), mientras que los sustantivos no humanos forman el plural con el sufijo -қәа (аеқәа 'caballos', азқәа 'аguas', алабақәа 'palos, varas') (Vid. Amichba, 2018).

\section{Nivel Sintáctico}

Según hemos indicado, la categoría de humanicidad afecta a diferentes niveles de la lengua. También en el nivel gramatical tiene su reflejo. Así, por ejemplo, en español el uso de la preposición a con complemento directo sigue una serie compleja de reglas en las que intervienen distintos factores entre los que se encuentran si se trata de nombre propio o común, de un referente determinado o indeterminado, tipo de verbo que rige el complemento directo, etc. (vid. Diccionario panhispánico de dudas (DPD), lema: $a^{2}$ ), pero en nuestra opinión uno de esos criterios sería la categoría de humanicidad. Veamos las siguientes reglas indicadas en el DPD:

\subsection{Uso forzoso:}

a) Ante nombres propios de persona o de animal: Vi a Pedro en el cine; Dejé a Pluto en la perrera.

g) Ante pronombres demostrativos o posesivos cuyo referente es una persona:

$V i$ a ese hablando con tu jefe; A ella no le gusta mi novio y yo no soporto al suyo.

$\mathrm{m}$ ) Ante nombres de cosa que designan colectivos formados por personas, del tipo colegio, empresa, comité, consejo, institución, comunidad, etc., cuando el verbo denota una acción que solo puede ejercerse sobre personas, y no sobre cosas: Multaron a la empresa por realizar vertidos tóxicos; Convocaron a la comunidad de vecinos para que tomara la decisión definitiva. 


\subsection{Doble uso:}

e) Los nombres comunes de animales se usan con preposición o sin ella en función de la mayor o menor proximidad afectiva existente entre el hablante y el animal: Suelta al caballo para que corra (mayor proximidad afectiva), frente a Suelta el caballo para que corra (menor proximidad afectiva). Por esta razón es muy frecuente el uso de la preposición con los nombres que designan animales domésticos, mientras que los nombres que designan animales no domésticos normalmente no admiten la preposición.

f) Ante nombres de cosa, el uso de la preposición depende del grado de personificación del referente: Esperó (a) la muerte con serenidad.

Como podemos observar, en la base de estas reglas citadas subyace la distinción entre ámbito humano y ámbito natural.

Así, la preposición a es obligatoria en casos de ámbito humano: nombres propios de persona o animales (los animales tienen nombre propio en el ámbito humano, aun cuando se le dé un nombre propio a un animal salvaje -por ejemplo, en estudios científicos-, el hecho de nombrarlo por parte de los seres humanos lo individualiza y lo incluye desde ese momento en el ámbito humano; repetimos que no estamos hablando de la categoría de "persona" o de "humano", sino de "ámbito humano", de cómo las lenguas naturales distinguen aquellas realidades que incluyen en la esfera de influencia de los humanos ${ }^{7}$ ), ante demostrativos o posesivos cuando se refieren a una persona y no a una cosa, ante colectivos formados por personas con verbos que designan acciones que solo puede ejercerse sobre personas y no sobre cosas, ante animales percibidos por el hablante como pertenecientes al ámbito humano (lo que la RAE entiende que es por "proximidad afectiva", aunque llega incluso a mencionar la distinción entre animales domésticos y no domésticos), o ante nombres de cosas personificadas.

La dificultad para percibir esta distinción reside, según nos parece, en que mientras que el uso de la preposición $a$ en complemento directo puede ser usado por la lengua como elemento marcador del ámbito humano, ello no implica que esté vetado su uso en ciertos casos de ámbito humano o que la elisión de la preposición sea algo exclusivo del ámbito natural, ya que, como hemos señalado, intervienen otros criterios en las reglas de uso de esta preposición (así por ejemplo, que el referente sea un objeto inanimado no personificado, en cuyo caso estará vetado el uso de la prepo-

Así, por ejemplo, Copito de Nieve, el famoso gorila blanco del zoológico de Barcelona, tenía un nombre propio y pertenecía al ámbito humano, frente a otros gorilas que viven en la naturaleza y que para los humanos no formarían parte del ámbito humano. 
sición -vid. 1.3, a) ${ }^{8}-$, lo que quiere decir que ante libro como complemento directo no se usará la preposición, aun cuando un libro pertenezca al ámbito humano).

En nuestra opinión otro ejemplo en español de la categoría de humanicidad es la distinción entre el pronombre acusativo lo y le. Etimológicamente el clítico masculino en acusativo era lo (del latín ILLUM, el femenino sería la de ILLAM), reservándose la forma le (de ILLI) para dativo. Sin embargo, ya desde los orígenes del castellano, dada su tendencia a distinguir los géneros, aparece el uso de la forma le como acusativo masculino de humanos, forma que alternará con lo. En el caso de masculinos no humanos la forma de acusativo del clítico será obligatoriamente lo. Como señala la RAE «El leísmo no se admite de ningún modo en la norma culta cuando el referente es inanimado: * El libro que me prestaste le lei de un tirón» (DPD). Adviértase que no sería correcto hablar de distinción entre masculino/ neutro para le y lo, ya que con animales no se usa le (-iHas visto a mi perro? - Lo vi esta mañana / ${ }^{*}$ Le vi esta mañana), sino que estamos ante una distinción entre humano/no-humano. Este ejemplo, no obstante, estrictamente hablando pertenece a la distinción gramatical entre humano/no-humano, lo que no coincide exactamente con nuestro objeto de estudio, pero pensamos, sin embargo, que esta tendencia a diferencia lo humano es también un reflejo de la distinción entre ámbito humano y ámbito no-humano que analizamos en el presente artículo.

La distinción en español entre el interrogativo ¿quién? y el interrogativo ¿qué? es también una diferencia entre ámbito humano/ámbito natural (y no simplemente entre humano/no-humano como tradicionalmente se piensa). Así por ejemplo, un hablante de español podría referirse cariñosamente a un perro u otro animal doméstico diciendo ¿Pero a quién tenemos aquí? ? cosa que no sería posible en el caso de un animal salvaje en su ámbito natural (excepto en usos con una intención literaria, irónica o de personificación). No ocurre así, por ejemplo, en ruso con los interrogativos kmo? [kto?] y umo? [sto??], donde $\kappa m o$ ? es traducido generalmente como '¿quién?', pero que se usa en realidad también para animales: Kmo эmo? ‘¿Qué es eso?' (referido a un animal), por lo que la distinción en ruso, como vemos, se basa en las categorías de animado/ inanimado, mientras que en español se basa en las categorías de ámbito humano/ ámbito natural. Esto interfiere en el aprendizaje y hemos registrado casos de hablantes rusos preguntando (refiriéndose a un insecto) ¿quién es? en vez de ¿qué es eso?

En niuano (lengua polinesia) existen clíticos usados específicamente para nombres de personas o pronombres. Así, la forma proclítica $a$ actúa como partícula con la función de indicar absolutivo en pronombres y nombres de persona. Puede

"1.3. No se usa:

a) Ante nombres comunes que designan objetos inanimados: Puso el libro en la mesa; Regaló un automóvil a su padre." (Diccionario panbispánico de dudas, lema $\boldsymbol{a}^{2}$ ). 
unirse a otros clíticos, como kia (partícula interrogativa) dando lugar a $k a$, por ejemplo: Hake ka koe he mouga? ‘ ¿Has subido (tú = koe) a la montaña?’.

En esta misma lengua se distinguía antiguamente entre nombres propios por el criterio de persona vs. no persona. Así, los nombres de persona expresaban el absolutivo siempre con las partículas a/ y el ergativo con $e$, mientras que los nombres propios de animales podían formarse también del mismo modo o específicamente con la partícula $e$ en absolutivo y la partícula he en ergativo; ejemplo: Ti ita ai e Feke ke he Kumā 'Y Pulpo (absolutivo) se enfadó con Rata (dativo)', donde este uso de $e$ como absolutivo y ke he como dativo no habría sido posible si se hubiera tratado de nombres de personas. Esta lengua posee también una serie de clasificadores entre los que podemos mencionar como pertinentes al presente artículo los de toko (clasificador para personas -ámbito humano-), ejemplo: e toko fà (e) tagata 'cuatro personas', pero fua (clasificador para frutos -ámbito natural-), ejemplo: e fā fua niu 'cuatro cocos') (vid. Polinskaya, 1995).

En abjasio, del que ya hemos mencionado que clasifica los sustantivos en humanos/no-humanos, los numerales distinguen a su vez dos formas para humanos/ no-humanos (vid. Amichba, 2018). Del 1 al 10 serían los siguientes:

\begin{tabular}{|c|c|c|}
\hline & No humanos & Humanos \\
\hline 1 & акы & азәы \\
\hline 2 & өба & өыџьа \\
\hline 3 & хпа & хөык \\
\hline 4 & நшьба & Ђшь৫ык \\
\hline 5 & хәба & хәюык \\
\hline 6 & фба & фөык \\
\hline 7 & быжьба & быжьөык \\
\hline 8 & ааба & ааюык \\
\hline 9 & жәба & жәюык \\
\hline 10 & жәаба & жәаюык \\
\hline
\end{tabular}

El árabe (lengua semítica) distingue en la concordancia con los adjetivos entre el plural de sustantivos referidos a seres racionales (humanos), con los que concuerdan en género, número y caso, y el plural de sustantivos referidos a no racionales o no humanos (animales, objetos inanimados, objetos y conceptos abstractos), con los que concuerda en femenino singular (vid. Corriente, 2006).

El sumerio (lengua aislada muerta de Mesopotamia) también distinguía los sustantivos en personales (humanos) e impersonales (no humanos), donde la clase de sustantivos personales incluía los referidos a seres humanos mientras que la de 
los impersonales englobaba animales, lugares, objetos inanimados o colectivos. Esta distinción afectaba a ciertos pronombres de tercera persona, a la formación del plural y a la formación del dativo personal. Así, aparte de otros recursos para formar el plural, como el de reduplicar el sustantivo con el sentido de totalidad "todos los...", en sumerio encontramos que una de las maneras es la adición del sufijo -(e)ne en el caso de sustantivos personales (lugal 'rey'/lugal-ene 'reyes'), mientras que el sufijo - hi-a se usaba para sustantivos impersonales (anše 'asno'/anše-hi-a 'asnos') y tenía más exactamente el sentido de "mezcla" o "surtido de" (en el caso de anše-hi-a podría significar 'varios asnos de diferentes edades y sexos').

Otros ejemplos en sumerio dentro del grupo de los personales serían el pronombre de tercera persona ane 'él' (no usado para no personales), el posesivo - ani 'suyo', el elemento - $n$ - en la cadena verbal, o el interrogativo $a b a$ ' ¿quién?'. Frente a ellos para los no personales encontramos que el posesivo es - $b i$ 'suyo', que en la cadena verbal el elemento usado es - $b$-, que el interrogativo es ana '¿qué?'.

La distinción humano/no-humano en sumerio afectaba también al sistema de casos, ya que algunos de ellos estaban restringidos a sustantivos personales (el dativo -ra) y otros estaban restringidos a no personales (locativo $-a$, locativo-terminativo $-e$, ablativo-instrumental $-t a$ ); el resto de casos podían aparecer tanto en personales como no personales. Compárese: ${ }^{d}$ Gilgameš en Kul-aba ${ }^{k i}-k e_{4} u r$-sag̈-bi-ne-er(a) gu $m u-n a-d e_{2}-e$ 'Gilgamesh, señor de Kulaba, habla a sus guerreros' (donde ur-sa $\tilde{g}$ 'héroe, guerrero -sustantivo personal- lleva el dativo -er) y $E_{2}$ gibil lugal kalam-ak-ene-ak-a 'en la casa nueva de los reyes del país' (donde $e_{2}$ 'casa' -sustantivo impersonal- está determinado por el locativo -a) (vid. Jiménez Zamudio, 1998; Foxvog, 2008).

Estos últimos ejemplos citados del abjasio, árabe y sumerio, aunque se refieren a la tradicional distinción gramatical entre humano/no-humano, nos pueden servir también para ejemplificar la tendencia a la distinción entre ámbito humano/ámbito natural (no-humano) analizada en el presente artículo.

\section{Conclusiones}

Las lenguas humanas presentan una tendencia a distinguir un mismo elemento, fenómeno, animal o vegetal según el hablante los considere circunscritos al ámbito humano o al ámbito natural (no humano). El conjunto de recursos lingüísticos para establecer dicha distinción da lugar a una auténtica categoría lingüística: la humanicidad. Las lenguas estructuran los recursos lingüísticos para manifestar esa categoría en el campo semántico-funcional de la humanicidad. Se trata de un campo-semántico funcional policéntrico de organización difusa que se vale de diversos medios de todos los 
niveles de la lengua y en el que es de especial importancia la distinción entre humano/ no-humano, pero no debe confundirse la distinción gramatical entre humano/no-humano con la distinción semántico-funcional entre ámbito humano/ámbito natural (la distinción por parte de los hablantes de una lengua dada del hecho de que un referente pertenezca a la esfera de influencia del ámbito humano o no, por ejemplo aquellos recursos lingüísticos que diferencian a los animales domesticados (ámbito humano) de los no domesticados (ámbito natural)), siendo la distinción gramatical humano/ no-humano un recurso más del campo semántico-funcional de la humanicidad.

Según hemos estado viendo a lo largo del artículo, los recursos lingüísticos para expresar la humanicidad son muy diferentes de una lengua a otra. Además, no son un conjunto de recursos sistematizados (no constituyen, por ejemplo, una categoría nominal o un modo verbal), se manifiestan discrecionalmente, no presentan un recurso dominante (campo semántico-funcional policéntrico) y, en ciertos casos (por ejemplo, el uso de la preposición $a$ en complemento directo en español), no son consistentes ni homogéneos en su uso. Quizá por todo ello esta categoría haya quedado en un segundo plano en las gramáticas y estudios clásicos. Los fenómenos lingüísticos estudiados en el presente artículo aparecen, por supuesto, en las descripciones de las distintas lenguas, pero todavía no se ha realizado un estudio global de conjunto sobre esta categoría, más allá de los numerosos estudios sobre subjetividad, antropocentrismo lingüístico, animacidad, distinción entre humano/no-humano etc., que, no obstante, según hemos mencionado, serían conceptos estrechamente relacionados con la humanicidad lingüística pero no totalmente identificables con ella.

\section{Bibliografía}

[Akademija Nauk SssR] AкаAEмия Наук Ссср (1980): Русская грамматика. 2 т., Москва, Наука.

Ambrazas, Vytautas (ed.) (1997): Lithuanian Grammar, Vilnius, Baltos Lankos. Aмicнва, Khibla (2018): The Abkhazian language and its place in the Caucasian family of languages, Abkhaz World: Online. En línea: <http://abkhazworld. com/aw/abkhazians/language/662-the-abkhazian-language> [20/01/2020].

[Arutjunova] Арутюнова, Нина Аавидовна (1999): Язык и мир человека, 2-е изА., испр., Москва, Языки русской культуры.

BACH, Emmon y HaRms, Robert Thomas (eds.) (1968): Universals in Linguistic Theory, New York, Holt, Rinehart \& Winson.

BALOdis, Uldis (2016): Yuki Grammar: With Sketches of Huchnom and Coast Yuki, Oakland, University of California Press. 
BeARD, Robert (1995): «The Gender-Animacy Hypothesis», Journal of Slavic Linguistics, 3(1), pp. 59-96.

Becker, Misha (2014): The Acquisition of Syntactic Structure: Animacy and Thematic Align-ment. Cambridge: Cambridge University Press.

Berlin, Brent y Key, Paul (1969): Basic Color Terms. Their Universality and Evolution, Berkeley-Los Angeles-Oxford, University of California Press.

[BondARKo] БонАAрко, Алексанар ВАадимирович (отв. реА.) (1987): Tеория функииональной грамматики: Введение. Аспектуальность. Временная локализованность. Таксис, АенинграА, Наука.

[BoNDARKo] БонАAРко, Алексанар ВАадимирович (отв. реА.) (1990): Tеория функииональной грамматики: Темпоральность. Модальность, АенинграА, Наука.

[BONDARKo] БонАAРКо, АлексанАр ВАадимирович (отв. реА.) (1992): Теория функциональной грамматики: Субъектность. Объектность. Коммуникативная перспектива высказвьвания. Определенность / неопределенность, Санкт-Петербург, Наука.

Bronnikov, G. y Krylov, Phil (1998-2014): Search for data in: Indo-European etymology / Harbour Project, Starling database server. En línea: $<$ http://starling.rinet.ru/cgi-bin/query.cgi ?basename $=\backslash$ data $\backslash$ ie $\backslash$ piet\&root $=$ config\&morpho $=0>[20 / 01 / 2020]$.

Collado Vega, José Antonio (2016): Peculiaridades percepto cognitivas: diferencias intralingüísticas en categorías de color básicas [tesis doctoral], Madrid, Universidad Complutense de Madrid. En línea <http://eprints.ucm. es/37646/1/T37207.pdf> [19/01/2020].

Comrie, Bernard (1989): Language Universals and Linguistic Typology. $2^{\text {nd }} e d$., Oxford, Basil Blackwell.

Corbett, Greville (1980): «Animacy in Russian and other Slavonic languages: Where Syntax and semantics fail to match», en Catherine Chvany \& Richard Brecht (eds.). Morpho-syntax in Slavic. Columbus, OH, Slavica.

Corriente, Federico (2006): Gramática árabe, Barcelona, Herder.

DAHL, Östen y FraURUd, Kari (1996): «Animacy in grammar and discourse», en T. Fretheim \& J. K. Gundel (Eds.). Reference and referent accessibility (pp. 47-64), Amsterdam, John Benjamins.

Duranti, Alessandro (1997): Linguistic Anthropology, Cambridge, Cambridge University Press.

FARTAKH, Adel (1997): La connotación y la idiosincrasia lingüistica y cultural (Asociaciones semántico-léxicas en el español de Granada y el árabe de Tetuán (Marruecos)), tesis doctoral, Granada. 
Foxvog, Daniel A. (2008): Introduction to Sumerian Grammar, Online: ANE Languages. En línea: <http://www.anelanguages.com/SumerianGrammarFoxvog. pdf $>[21 / 01 / 2020]$.

Fraser, Norman y CorbetT, Greville (1995). «Gender, animacy and declensional class assignment: a unified account for Russian », en Geert Booij \& Jaap van Marle (eds) Yearbook of Morphology 1994 (pp. 123-50). Dordrecht, Kluwer.

Gardin Dumesnil, Jean Baptiste (1809): Latin Synonyms, with Their Different Significations, and Examples Taken from the Best Latin Authors, London, Richard Taylor and Co.

Helasvuo, Marja-Liisa y Campbell, Lyle (2006): Grammar from the Human Perspective: Case, space and person in Finnish, Amsterdam/Philadelphia, John Benjamins Publishing Company.

Jiménez Ruiz, Juan Luis (1986): «Notas para una teoría de la explicación del significado connotativo», Analecta malacitana, 9 (2), pp. 407-418.

Jiménez Zamudio, Rafael (1998): Gramática de la lengua sumeria, Madrid, Ediciones clásicas.

KLenin, Emily (1983): Animacy in Russian: a new interpretation. UCLA Slavic Studies, 6. Columbus, Slavica.

[Krivonosov] Кривоносов, Алексей Тимофеевич (2012): Философия языка, Москва, Азбуковник.

Leech, Geoffrey N., Francis, Brian J. y Xu, Xunfeng (1994): «The use of computer corpora in the textual demonstrability of gradience in linguistic categories», en C. Fuchs \& B. Victorri (eds.). Continuity in Linguistic Semantics (pp. 57-76), Amsterdam, John Benjamins.

LAKoff, George (1987): Women, Fire and Dangerous Things: What categories reveal about the mind, Chicago, The University of Chicago Press.

LuQe Durán, Juan de Dios (2001): Aspectos universales y particulares del léxico de las lenguas del mundo, Granada, Método Ediciones.

Mclaughlin, Brittany Dael (2014): «Animacy in Morphosyntactic Variation». Publicly Accessible Penn Dissertations, 1365. En línea: <http://repository. upenn.edu/edissertations/1365> [20/01/2020].

Marlett, Stephen A. (2012): «La Animacidad», en Stephen A. Marlett (ed.) Los Archivos Lingüisticos Me’phaa. SILInternational <http://www.sil.org/mexico/ workpapers/WP013-PDF/MephaaAnimacidad.pdf $>$.

[Maslova] Маслова, Валентина Авраамовна (2004): Аингвокульурология. 2-е иза., Москва, Academia. 
PAlmer, Frank Robert (1986): Mood and modality, Cambridge, Cambridge University Press.

[Polinskaya] Полинская, Мария Семеновна (1995): Языћ ниуэ, Москва, Восточная митература РАН.

Real Academia Española De La Lengua (2019): Diccionario panbispánico de dudas, Madrid, RAE. En línea: <http://www.rae.es/recursos/diccionarios/ $\mathrm{dpd}>[20 / 12 / 2019]$.

REY, Joëlle (1999-2000): «Subjetividad y gradualidad en las relaciones lógicas», Sendebar, 10-11, pp. 185-198.

RoBerts, Edward y PASTOR, Bárbara (2009): Diccionario etimológico indoeuropeo de la lengua española, Madrid, Alianza Editorial.

Siemund, Peter (2011): Linguistic Universals and Language Variation, Berlin-New York, De Gruyter Mouton.

Simone, Raffaele y Masini, Francesca (2014): Word classes: nature, typology and representations, Amsterdam-Philadelphia, John Benjamins.

Sorlin, Sandrine y GARDELle, Laure (2018): «Anthropocentrism, egocentrism and the notion of Animacy Hierarchy», International Journal of Language and Culture, From Culture to Language and Back: The Animacy Hierarchy in language and discourse, 5 (2), En línea: < https://hal.archives-ouvertes.fr/hal01874511 document $>[21 / 01 / 2020]$.

[Stepanov] СтеПАНов, Юрий (2004): Константы: словарь русской культуры, 3-е изА. исправ. и Аополн., Москва, Академический проект.

[Vol'f] ВОАЬФ, Елена Моисеевна (2002): Функционацьная семантика оценки. 2-е, изА., Аоп., Москва, УРСС.

[Voroв’ёv] Вороььёв, Владимир Васильевич (1994): Культурологическая парадигма русского языка: Теория описания языка во взаимодействии, Москва, Институт Русского Языка имени А.С. Пушкиня.

VV.AA. (2019): The free dictionary, Huntingdon Valley: Farlex. En línea <http:// www.thefreedictionary.com $>[15 / 12 / 2019)$.

Wittgenstein, Ludwig (2017): Tractatus logico-philosophicus / Investigaciones filosóficas (traducción y edición de Isidoro Reguera Pérez), Madrid, Gredos.

Yamamoto, Mutsumi (1999): Animacy and reference: A cognitive approach to corpus linguistics, Amsterdam, John Benjamins.

Yip, Po-Ching y Rimmington, Don (2015): Gramática de la lengua china, Madrid, Cátedra.

Fecha de recepción: 25 de abril de 2019 Fecha de aceptación: 25 de enero de 2020 